\title{
An Implicit Measure of Sexual Double Standard Endorsement in Emerging Adults: Reliability and Validity Aspects
}

\author{
Jacques J. D. M. van Lankveld ${ }^{1}$ (D) Peggy M. J. Emmerink ${ }^{2}$. \\ Regina J. J. M. van den Eijnden ${ }^{2}$. Tom F. M. ter Bogt ${ }^{2} \cdot$ Ron J. Pat-El $^{1}$. \\ Ine Vanwesenbeeck ${ }^{2}$
}

Accepted: 25 September 2021 / Published online: 7 October 2021

(c) The Author(s) 2021

\begin{abstract}
Psychometric characteristics were investigated of an Implicit Association Test to assess implicit endorsement of the sexual double standard (SDS-IAT) in emerging adults. The reliability of the SDS-IAT was investigated focusing on internal consistency across different phases of the test. Convergent validity of the SDS-IAT was evaluated against the Scale for the Assessment of Sexual Standards in Youth, an explicit measure of SDS, and against gender investment. Divergent validity was evaluated against the personality characteristics of extraversion, neuroticism, and social desirability proneness. Gendered patterns were examined. Attenuation-corrected alphas demonstrated acceptable internal consistency, with alphas ranging for .65-.70. A modest level of explicit SDS endorsement was found in both female and male participants. In line with their explicit SDS level, a modest level of implicit SDS endorsement was found in male participants, whereas a reverse implicit SDS was found among young women. In agreement with our theoretical expectations, we found low convergent validity in multitrait-multimethod analysis of the SDS-IAT with a measure of explicit SDS endorsement, and with general level of investment in gender ideals. Similarly, divergent validity analysis revealed absence of significant correlations with the conceptually unrelated concepts of extraversion, neuroticism, and social desirability proneness, except for extraversion in female participants. The present findings suggest that implicit SDS endorsement can be assessed using the SDS-IAT. The finding that explicit and implicit SDS approvals differ in young female participants, while they align in young male participants, warrants further research.
\end{abstract}

Keywords Sexual double standard - Emerging adulthood - Implicit attitudes · Explicit attitudes $\cdot$ Gender differences

Jacques J. D. M. van Lankveld

jacques.vanlankveld@ou.nl

Extended author information available on the last page of the article 


\section{Introduction}

Sexual double standards (SDS), originally conceptualized as the divergent evaluation of male and female extramarital sexual relations, have gradually come to be understood as a broader set of normative gender-specific expectations for boys and girls for engaging in romantic and sexual behavior (Crawford \& Popp, 2003; Vanwesenbeeck, 2009). A central aspect of the SDS regards sexual assertiveness: boys are expected to be sexually active, dominant, and to take initiative for sexual contact, whereas girls are expected to be sexually reserved, submissive, and passive (Emmerink et al., 2016a, 2016b). The SDS regards a specific application of a more general propensity for investment in gender ideals, briefly referred to as 'gender investment', reflecting the extent to which boys and girls, and men and women believe it to be important to adhere to the ideals or standards for their own gender (Sanchez \& Crocker, 2005; Wood et al., 1997).

Level of endorsement of the SDS has been found to be associated with the judgement of sexual behavior of both close friends and more distant acquaintances (Marks et al., 2019). Endorsement of (aspects of) the sexual double standard has also been associated with a variety of negative sexual health outcomes (Sanchez et al., 2012). For boys, it has been related to increased rape myth acceptance (Truman et al., 1996), and beliefs that dating violence is acceptable, potentially passing into subsequent sexually violent behavior (Shen et al., 2012). For both boys and girls, SDS endorsement has been related to early sexual initiation (Goncalves et al., 2008; Part et al., 2011) and higher STI/HIV infection risk (Bermudez et al., 2010). Although all young people are susceptible to the potential negative impact of SDS adherence, the impact seems particularly relevant for girls (Sanchez et al., 2012). For them, the sexual passivity associated with SDS endorsement is predictive of experiencing more negative and fewer positive emotions with regard to sex (Emmerink et al., 2016a, 2016b), lower sexual satisfaction (Kiefer \& Sanchez, 2007), and higher odds for experiencing sexual problems (Sanchez \& Kiefer, 2007).

However, research findings regarding the existence, impact and stability of sexual double standards, as well as the deleterious effects of their endorsement have been equivocal and conclusions based on them vary. For some time now, researchers have argued that the sexual double standard no longer exists (Marks \& Fraley, 2005, 2006); that it only exists under certain circumstances, such as when engagement in uncommon types of sexual behavior, including "threesomes", is evaluated (Jonason \& Marks, 2009); or that the SDS is a local construction, differing across ethnic and cultural groups (Crawford \& Popp, 2003; Sanchez et al., 2012). Other researchers have reported a reverse sexual double standard (Milhausen \& Herold, 1999, 2001; Sakaluk \& Milhausen, 2012), by which women judge male sexual behavior more critically than women's behavior.

Several explanations for these inconsistent findings in previous studies have been suggested, including the use of self-report methods (Crawford \& Popp, 2003), of outdated questionnaire measures (Bordini \& Sperb, 2013), of predominantly university student samples (Bordini \& Sperb, 2013; Emmerink et al., 
2016a, 2016b; Fugère et al., 2008), and the lack of theory-driven empirical research (Zaikman \& Marks, 2017).

In particular the use of self-report measures to assess SDS is questionable as it has been shown that these measures suffer from social desirability bias in, for example, studies on sexual topics such as pornography-related self-reports (Rasmussen et al., 2018), or young men's self-reports of their penis size (King et al., 2019). Similarly, self-report instruments for SDS endorsement may also be seriously biased by social desirability demands (Sakaluk \& Milhausen, 2012).

Indirect measures of SDS endorsement such as the Implicit Association Test (IAT; Greenwald et al., 1998), tapping into automatic cognitions, may bear advantages over self-report measures (Zapata-Calvente et al., 2019). The IAT has, in its relatively brief history, become known as a psychometrically sound instrument (Cunningham et al., 2001) that is able to capture individuals' implicit associations between semantic categories (Greenwald et al., 1998). Inter-item consistency estimates (split-half correlations or alpha's) of IAT indices were found to range from 0.7 to 0.9 (Cunningham et al., 2001; Nosek et al., 2007), but have been generally found to be somewhat lower than similar estimates of self-report instruments (Cunningham et al., 2001). Across studies, the IAT test-retest reliability was found to be rather stable, with a median $r=0.56$, and to show little variability associated with the length of the retest interval (Mierke \& Klauer, 2003; Nosek et al., 2007). With regard to different aspects of construct validity, IAT measures have generally shown relatively low convergence both with other IATs and explicit measures, intended to measure the same constructs. In a meta-analysis a mean effect size of $r=0.24$ was found of the correlations between IATs and explicit self-report measures of the same constructs (Hofmann et al., 2005). These observations seem to imply that implicit and explicit measures, despite their apparent similarity, represent different phenomena. Note that several authors warned that the upper limit of the possible correlations of an IAT with other measures is constrained by the limited reliability of implicit measures and, relatedly, that higher levels of measurement error may result in attenuated estimates of test-retest reliability and of convergent validity (Cunningham et al., 2001; Nosek et al., 2007).

Nevertheless, there is broad agreement in the literature that IAT measurement bypasses introspective self-report (Nosek et al., 2007), in the sense that it can reveal automatic associations with certain stimuli of which the individual may not be aware. This would make IAT measurement less susceptible to demand effects, including socially desirable response tendencies, resulting in more valid measurement. It has also been argued that the IAT is more ecologically valid than other measures of automatic cognition including the divided attention task (Marks, 2008), and more closely resembles sexual evaluation as it occurs in real life, because IAT measurement bypasses more deliberate cognitive processes (Sakaluk \& Milhausen, 2012). Considering that the SDS is a stereotype (Vanwesenbeeck, 2011), it can be expected to influence cognition and behavior through more automatic cognitive processes that the IAT taps into, as opposed to more controlled cognitions that can be measured using self-report instruments.

Because automatic and controlled processes interact in social cognitive processing (Cunningham \& Zelazo, 2007), assessment of both implicit and explicit 
cognitions may be relevant when examining SDS endorsement. Explicit questionnaire measures of SDS endorsement might reflect one's conscious and deliberate endorsement of perceived societal norms, whereas implicit measures might better reflect one's automatic cognitive responses to sexual cues, reflecting the degree to which one has internalized societal norms. The two types of assessment presumably each tap into unique sources of variance, which may or may not overlap (Cunningham et al., 2001; Nosek et al., 2007). Therefore, implicit measurements may provide different and additional information on an individuals' degree of SDS endorsement, complementing the explanatory power of explicit attitudes.

In support of this claim, in a previous study using IAT methodology (Sakaluk \& Milhausen, 2012), implicit and explicit measures of SDS endorsement were found to yield divergent findings. Both men and women endorsed the SDS when it was measured using a self-report questionnaire (the Sexual Double Standard Scale; Muehlenhard \& Quackenbush, 1996), with men holding a stronger traditional double standard, compared to women. However, when SDS endorsement was measured using an IAT, a relatively gender-neutral evaluation was found among men, and a strong reverse sexual double standard among women (Sakaluk \& Milhausen, 2012). Specifically, women responded faster when the category 'female' was paired with the attribute 'sexually positive', compared to when it was paired with 'sexually negative'. The findings in this study that were based on the self-report measure thus matched findings from many previous studies (in which self-report measures have also frequently been used), whereas the results from the implicit measure painted a completely different picture. This suggests the existence of a more complex double standard involving different levels of cognitive processing, warranting further research using indirect measurements that tap into automatic cognitive processing.

Note, however, that in the IAT of Sakaluk and Milhausen (2012) the category labels (male vs. female, and sexually positive vs. sexually negative) and the word stimuli (e.g., clean for sexually positive, and dirty for sexually negative) representing them do not refer to behavioral aspects of sexuality which are essential for the sexual double standard. Instead of assessing implicit sexual double standard endorsement, this IAT may thus have assessed the extent to which respondents implicitly associate male or female gender with positive vs. negative sexual experiences. Therefore, the aim of the present study was to investigate a new IAT, which employs category labels and stimuli that are semantically closer to the aspects of behavior that are evaluated in the sexual double standard.

\section{The Present Study}

Thus, the rationale of the present study is based on previous conflicting research findings regarding the existence, impact and stability of sexual double standards, the criticism that these inconsistencies may be caused by instrumentation problems (reliance solely on self-report tools and the use of outdated questionnaires), and the suggestion that SDS endorsement could be better measured by using indirect measures of implicit SDS endorsement, for which initial empirical support has been found (Sakaluk \& Milhausen, 2012). 
The present study aimed to evaluate the internal consistency, and the convergent and divergent validity of a new implicit association test (the SDS-IAT), that is aimed to measure implicit endorsement of the SDS. Gender is included in the analyses as it is a crucial factor in the study of SDS endorsement. Data were collected in a community sample, in order to avoid investigating a sample exclusively comprised of university students. As to the investigation of the validity of the SDS-IAT, its convergent validity will be evaluated against explicit SDS endorsement using questionnaire data, and against general gender investment. Based on previous meta-analytic data (Hofmann et al., 2005), a limited effect size $(0.20>d>0.30)$ is expected of the correlation between the SDS-IAT and explicit SDS endorsement. Also, a limited effect size is expected of the correlation between the SDS-IAT and gender investment. Divergent validity will be examined against social desirability, and against aspects of personality, also using questionnaire data. This decision was based on research showing that IAT attitudes were significantly related to self-reported measures of corresponding constructs, but not to social desirability and to other personality traits that are considered unrelated (Nosek et al., 2007; Slabbinck et al., 2013; Vecchione et al., 2017). Limited effect sizes are expected of the correlations between the SDS-IAT scores and social desirability, and the personality traits of extraversion and neuroticism.

The new IAT was based on a relatively broad definition of SDS endorsement as 'the degree to which an individual's attitude reflects a divergent set of expectations for boys and girls, in that boys are expected to be relatively more sexually active, assertive, and knowledgeable and girls are expected to be relatively more sexually reserved, passive, and inexperienced' (Emmerink et al., 2016a, 2016b).

The development of an IAT typically begins with the selection of target and attribute categories and their labels, aiming to represent the concepts of interest. Next, stimuli are selected that serve as exemplars of these conceptual categories (Brenner et al., 2019; De Houwer, 2001; Fazio \& Olson, 2003; Nosek et al., 2007). Therefore, the concepts of interest for the new SDS-IAT are: gender (male, female) and two opposing classes of sexual behavior ('sexually active' versus 'sexually passive'). The selection of category labels and stimuli in this study will be further reported in the Methods section.

Regarding the terminology of the relevant constructs in the field of IAT assessment, we follow Moors et al. (2010), and will (1) use the term 'automatic' when the underlying cognitive process is addressed; (2) use the term 'indirect' when referring to the assessment procedure; and (3) speak about 'implicit' when referring to the association between the concepts of interest and the instruments that are used to measure them, including the IAT.

\section{Method}

\section{Design}

A cross-sectional study was conducted. Participants completed questionnaires and performed online computer tasks in a single session. 


\section{Sample}

Sexually active, heterosexual, emerging adults between the age of 18 and 25 in the general community were eligible for participation. Good command of the Dutch language was required. Based on these inclusion criteria, a convenience sample of 159 participants was taken. Participants resided in the Netherlands or in Flanders, Belgium. They were recruited by undergraduate psychology students of the Open University of the Netherlands in their circles of acquaintances by sending out personal invitations by email. Because of the distance education system of the university, the geographical distribution of the participant's places of residence was wide. After removing data of participants who did not complete the IAT, 134 participants remained. Based on a sexual orientation question, data of three gay men ("only or mostly attracted to men"), two bisexual men ("attracted both to men and women"), one lesbian woman ("only attracted to women"), four bisexual women, and ten participants who were uncertain of their sexual orientation or did not wish to share this information, were removed from data analysis in order to assure sample's specificity in terms of sexual orientation. Data of one participant was removed because the extreme number of invalid responses to both IATs $(30 \%)$ made the researchers doubt the sincerity of the respondent's participation. Finally, data of two participants were removed who reported remarkably high lifetime numbers of sexual partners for people in their age category, respectively 50 and 36. The final sample retained for data analysis consisted of 111 heterosexual emerging adults $\left(\mathrm{N}_{\text {female }}=75[67.62 \%], M_{\mathrm{age}}=22.1, S D_{\mathrm{age}}=1.9\right)$.

\section{Procedure}

Ethical approval was obtained from the Utrecht University Ethics Committee (filed under reference FETC-14024; Vanwesenbeeck). To reduce bias due to social demands, participants completed the questionnaires and performed the computer tasks in the comfort of their own home using an online research platform. Online assessment of the IAT has been found to produce robust findings that do not differ from assessments in a lab setting (Houben \& Wiers, 2008; Nosek et al., 2002). Participants first completed either the SDS-IAT or an IAT assessing implicit sexual assertiveness. Data from the latter IAT will not be reported here. The order of both IATs was randomly assigned by the computer. After completing the IATs, participants completed the questionnaires of the study in a fixed order. Completing the study took about $30 \mathrm{~min}$. After finishing the final task, participants received an email with a debriefing message and a digital gift voucher of 10 euros. 


\section{Instruments}

\section{Demographics}

Participants indicated their age, gender (closed question with 2 answering options: female, male), lifetime number of sexual partners and sexual orientation (on a five-point scale ranging from ' $1=$ exclusively attracted to men' to ' $5=$ exclusively attracted to women'). Respondents were considered sexually active if the reported lifetime number of partners question was 1 or higher.

\section{Implicit SDS Endorsement}

An IAT (Greenwald et al., 1998) was designed to measure implicit SDS endorsement (SDS-IAT). Target category labels were 'male' versus 'female', and attribute category labels were 'sexually active' versus 'sexually passive'. Stimulus words were presented in the middle of the screen. Words representing the target categories were Dutch male (i.e. Bram, Tim, Rob, Jan) and female names (i.e. Emma, Lieke, Julia, Roos). Words representing the 'sexually active' attribute category were 'sexual', 'exciting', 'experienced', and 'daring' (translated from the Dutch words 'seksueel', 'opwindend', 'ervaren', 'uitdagend'). Words representing the 'sexually passive' attribute category were 'biding', 'reserved', 'cautious', 'modest' (translated from the Dutch words 'afwachtend', 'terughoudend', 'voorzichtig', 'bescheiden'). Male and female names were taken from a list of common Dutch names. Only names that the researchers judged to be non-ambiguously male or female were chosen. Target words associated with the 'sexually active' versus 'sexually passive' attribute categories were chosen based on pretesting among 200 participants (50\% female), who were presented 20 words per attribute. Words that had the strongest associations with the attribute labels, and did not show gender differences, were selected. The labels of the target and attribute categories were permanently visible in the upperleft and -right corners of the screen. After a correct response, the next stimulus was

Table 1 Sequence of Trial Blocks in the IAT-SDS

\begin{tabular}{|c|c|c|c|c|}
\hline Block & No. of trials & Function & $\begin{array}{l}\text { Items assigned to left-key } \\
\text { response }\end{array}$ & $\begin{array}{l}\text { Items assigned to right-key } \\
\text { response }\end{array}$ \\
\hline $\begin{array}{l}1 \\
2 \\
3 \\
4 \\
5\end{array}$ & $\begin{array}{l}16 \\
48 \\
16 \\
48\end{array}$ & $\begin{array}{l}\text { Attribute practice } \\
\text { Practice } \\
\text { Test } \\
\text { Practice } \\
\text { Test }\end{array}$ & $\begin{array}{l}\text { Sexually Active (8) } \\
\text { Sexually Active (4)+ Male } \\
\quad(4) \\
\text { Sexually Active (12)+ Male } \\
\quad(12) \\
\text { Sexually Active (4)+ Female } \\
\quad(4) \\
\text { Sexually Active } \\
\text { (12)+Female (12) }\end{array}$ & $\begin{array}{l}\text { Sexually Passive (8) } \\
\text { Sexually Passive (4) + Female } \\
\text { (4) } \\
\text { Sexually Passive (12)+Female } \\
\quad(12) \\
\text { Sexually Passive (4) + Male (4) } \\
\text { Sexually Passive (12)+ Male } \\
\quad(12)\end{array}$ \\
\hline
\end{tabular}

For half the subjects, the positions of Blocks 2 and 3 are switched with those of Blocks 4 and 5, respectively

IAT-SDS Implicit Association Test for Sexual Dual-Standard Endorsement 
presented after a $250 \mathrm{~ms}$ interval. After an incorrect response, a red X appeared that replaced the stimulus and remained on the screen until the correct key was pressed.

The SDS-IAT was organized in five blocks, see Table 1 for details. To familiarize participants with the procedure, the SDS-IAT started with a practice run of 16 trials presenting only stimuli from the target category (gender: 'male' versus'female'; block 1). Next was a practice block of 16 trials (block 2) in which both target and attribute stimuli were presented, followed by a test block of 48 trials (block 3). In these two blocks, one of two possible combinations of target and attribute categories (female + sexually passive; male + sexually active) were mapped on the response keys (' $z$ ', and ' $\mathrm{m}$ ' on a QWERTY keyboard). In the final blocks, a practice (block 4) and a test block (block 5), including the same numbers of trials, the reverse combination was presented (male + sexually passive; female + sexually active). Two versions of this SDS-IAT were made. They differed in the order of presentation of blocks $2+3$ and $4+5$, thus allowing to investigate potential order effects. Random allocation ensured that half of the participants started with each version.

\section{Explicit SDS Endorsement}

To assess explicit SDS endorsement the Scale for the Assessment of Sexual Standards in Youth (SASSY) was used (Emmerink et al., 2017). The SASSY contains 19 items and was designed as a multifaceted measure of SDS endorsement suitable for young people, contributing to a single underlying factor. An example item is 'Sometimes a boy should apply some pressure to a girl to get what he wants sexually'. Answers were given on a 6-point scale ranging from ' $1=$ Completely disagree' to $6=$ Completely agree'. In previous research good reliability was found among Dutch adolescents $(\alpha=0.90$; Emmerink et al., 2017) and young adults (Study $1 \alpha=0.88$, Study $2 \alpha=0.89$; Emmerink et al., 2017). In the present study a Cronbach's $\alpha$ of 0.85 indicated good internal consistency. A mean score was calculated of all items. Higher scores represent higher level of SDS endorsement.

\section{Gender Investment}

Gender investment was assessed using two questions: "How important is it for you to be similar to the ideal man/woman?" and "To what extent is being similar to the ideal man/woman an important part of who you are?" (Good \& Sanchez, 2010). Answers were given on a ten-point scale from ' $1=$ not important at all' to ' $10=$ very important'. The mean score of the two items was used in the analyses. Scores on both questions correlated significantly $\left(r_{\text {women }}=0.43, p<0.001 ; r_{\text {men }}=0.30, p<0.05\right.$ ).

Personality characteristics The Eysenck Personality Questionnaire (revised, short version (EPQ-R); Eysenck \& Eysenck, 1975; Dutch adaptation: Sanderman et al., 1991) is a 48-item self-report questionnaire for the measurement of the traits of psychoticism, neuroticism, extraversion and social desirability. For the present study extraversion, neuroticism, and social desirability ('lie scale') were used. The possible range of subscale scores is $0-12$. Higher scores represent stronger personality traits. In previous research satisfactory reliability was found for all factors (Cronbach's $\alpha$ between 0.69 and 0.86), except for the psychoticism dimension among Dutch men (Cronbach's 
$\alpha=0.62$ ) (Sanderman, Eysenck, and Arrindell 1991). In the present sample Cronbach's $\alpha$ 's were found to range from 0.67 (Social Desirability) to 0.83 (Extraversion), indicating satisfactory reliability.

\section{Statistical Analysis}

The D600 algorithm of Greenwald et al., (2003) was employed to calculate scores of implicit SDS endorsement. Only test block data were used. Reaction times (RTs) below $400 \mathrm{~ms}$ were discarded and those higher than $2500 \mathrm{~ms}$ were replaced with 2500 before calculation of the mean RTs. Error trial RTs were replaced with the mean RT of the participant's correct responses in the same block in which the error occurred plus a $600 \mathrm{~ms}$ penalty. The D600 index score was calculated as the difference score between the mean RTs, divided by the pooled standard deviation with the exception of the attribute practice block. A negative SDS-IAT score reflects higher implicit SDS endorsement with stronger associations between "male" and "sexually active" and between "female" and "sexually passive". Inversely, a positive SDS-IAT score reflects endorsement of a reverse SDS. Scores close to 0 reflect absence of a dual sexual standard in either direction.

The internal consistency of the SDS-IAT was calculated by measuring the splithalf reliability by correlating D600 scores of the even trials with the odd trials within each block. Because the D600 indices are calculated as difference scores, its reliability is impacted by the sampling error in both its constituent parts, decreasing when the correlation between those parts increases. Given the unlikelihood that the correlation between constituent parts is zero, the reliability of the D600 requires a correction for this error-attenuation (Cohen et al., 2014) to compensate for the error in opposing blocks, and the correlation between the blocks.

Differences between men and women were examined. We evaluated whether there were order effects (both in the order of both IATs, and within IAT opposing block order), or effects of the number of errors on the implicit and explicit scores. These variables were controlled for in the regression analyses in case they showed significant effects in the preliminary analyses. Convergent and divergent validity were investigated in a multitrait-multimethod approach by, firstly, inspecting the bivariate correlations in the female and male subsamples of the SDS-IAT with instruments measuring both neighboring and unrelated constructs on SDS-IAT scores. Additionally, to control for method-related confounders and to examine gender effects, a hierarchical multiple regression analysis was conducted with SDS-IAT scores as criterion variable. All variables in the theoretical model were standardized before entering the regression analysis. Analyses were carried out using IBM SPSS ${ }^{\mathrm{TM}}$, Version 24.0. Reliability analysis and correction for attenuation was performed using R (R_Core_Team, 2021). A general alpha-threshold of $5 \%$ was used to determine significant findings. 
Table 2 Demographic characteristics and sexual variables

\begin{tabular}{|c|c|c|}
\hline & Men (M(SD); \%) & Women (M(SD); \%) \\
\hline Age & $21.8(1.9)$ & $22.2(1.9)$ \\
\hline \multicolumn{3}{|l|}{ Education Level } \\
\hline Lower & 10.5 & 2.2 \\
\hline Intermediate & 66.7 & 60.7 \\
\hline Higher & 22.9 & 37.1 \\
\hline \multicolumn{3}{|l|}{ Relationship Status $^{\mathrm{a}}$} \\
\hline Single & 38.2 & 29.2 \\
\hline Dating & 20.0 & 6.3 \\
\hline Committed Relationship & 40.0 & 62.5 \\
\hline Married & 1.8 & 2.1 \\
\hline \multicolumn{3}{|l|}{ I Feel Sexually Attracted } \\
\hline Only to Men & 9.1 & 69.8 \\
\hline Mostly to Men & 1.8 & 24.0 \\
\hline Both to Men and Women & 3.6 & 4.2 \\
\hline Mostly to Women & 10.9 & 0.0 \\
\hline Only to Women & 72.7 & 1.0 \\
\hline Don't know (yet) & 0.0 & 1.0 \\
\hline Not Disclosed & 1.8 & 0.0 \\
\hline \multicolumn{3}{|l|}{ Open for a New Relationship } \\
\hline Not at all & 32.7 & 40.6 \\
\hline A Little Bit & 36.4 & 20.8 \\
\hline Positive & 14.5 & 15.6 \\
\hline Very Much & 19.4 & 22.9 \\
\hline
\end{tabular}

${ }^{\mathrm{a}}\left(\chi^{2}(3)=10.0, p<.02\right)$

\section{Results}

Demographic features of the sample and scores on sexual variables are shown in Table 2. Mean ages and education level of female and male participants were not significantly different. Level of openness for a new relationship was not different between male and female participants. However, compared with male participants, female participants more often reported being in a committed relationship $\left(\chi^{2}(1)=6.93, p<0.01\right)$.

\section{Internal Consistency}

Calculation of the split-half reliability for the practice trials yielded a $\alpha=0.87$; for the test trials $\alpha=0.95$; for combined practice and test trials $\alpha=0.95$. After correction for attenuation, we found $\alpha=0.65$ for the practice trials, $\alpha=0.70$ for the test trials, and $\alpha=0.67$ for combined practice and test trials. 


\section{Method-Specific Determinants of Implicit Sexual Double Standard Endorsement}

To examine order effects on implicit SDS endorsement a two-way ANOVA was performed with SDS-IAT scores as the dependent variable and order of presentation of both combinations of target and attribute categories within the SDS-IAT and order of presentation of both IATs (See Procedure) as independent factors. A significant main effect of within-IAT presentation order was found $(F(1,108)=11.2, p=0.001)$. Response latencies were smaller when the combination of "female" + "sexually passive" and "male + sexually active" was presented first, compared with the reverse presentation order. Presentation order of both IATs was not significant $(p>0.05)$. For further analyses, data of both IAT orders were collapsed. In male participants, SDS-IAT scores were significantly correlated with number of valid IAT responses $(r=0.36, p<0.05)$. Higher number of valid responses was associated with lower implicit SDS endorsement. This correlation was not significant in female participants. In order to determine whether within-IAT presentation order, and number of valid IAT trials could be treated as true covariates it had to be shown that they were not covariant with other predictors of implicit SDS endorsement. Bivariate correlations of these factors with explicit SDS endorsement, gender investment, extraversion, neuroticism, and social desirability were calculated separately in male and female participants. No significant correlations were found, except for within-IAT order and extraversion $(r=31, p=0.006)$ in female participants. Within-IAT presentation order, and number of valid IAT trials were therefore controlled for in further analyses as covariates.

\section{Gender Differences}

The mean scores and standard deviations across gender of the core variables are presented in Table 3. Young men's mean SDS-IAT score was negative; their implicit associations of 'male' with 'sexually active' and 'female' with 'sexually passive' were stronger than the associations of 'male' with 'sexually passive' and 'female' with 'sexually active', reflecting implicit endorsement of the sexual double standard. Young women, on the other hand, were found to have a positive mean

Table 3 Means and standard deviations among young men and women

\begin{tabular}{|c|c|c|c|c|c|c|}
\hline & \multicolumn{2}{|c|}{$\begin{array}{l}\text { Young men } \\
(\mathrm{n}=36)\end{array}$} & \multicolumn{2}{|c|}{$\begin{array}{l}\text { Young women } \\
(\mathrm{n}=75)\end{array}$} & \multicolumn{2}{|c|}{$\begin{array}{l}95 \% \text { confidence } \\
\text { interval }\end{array}$} \\
\hline & $\mathrm{M}$ & $\mathrm{SD}$ & M & SD & Lower & Upper \\
\hline Implicit SDS Endorsement (IAT-SDS) $* * *$ & -.16 & .40 & .08 & .34 & -.39 & -.10 \\
\hline Explicit SDS Endorsement (SASSY) & 2.29 & .69 & 2.21 & .55 & -.16 & .32 \\
\hline Gender Investment & 6.46 & 1.53 & 6.71 & 1.29 & -.80 & .30 \\
\hline Extraversion (EPQ-R)* & 9.25 & 2.60 & 8.01 & 2.96 & .10 & 2.39 \\
\hline Neuroticism (EPQ-R)* & 4.11 & 2.94 & 5.68 & 3.23 & -2.83 & -.31 \\
\hline Social Desirability (EPQ-R)* & 4.64 & 2.22 & 5.71 & 2.41 & -2.01 & -.12 \\
\hline
\end{tabular}

Participants whose data were used in main analyses; ${ }^{*} p<.05 ; * * p<.01 ; * * * p \leq .001$ 
SDS-IAT score, indicating an implicit endorsement of a reverse double standard; their implicit associations of 'female' with 'sexually active' and 'male' with 'sexually passive' were stronger than the associations of 'female' with 'sexually passive' and 'male' with 'sexually active'. This gender difference was statistically significant $(t(109)=3.32, p<0.001, d=0.66)$. One-sample t-tests were conducted to further examine whether the separate mean scores on the SDS-IAT for young men and women were also significantly different from zero, which was the case both for young men $(t(35)=-2.41, p=0.021, d=-0.4)$ and young women $(t(74)=2.10$, $p=0.039, d=2.35)$. No significant gender differences were found on the explicit sexual double standard measure (SASSY; $t(109)=0.68, p=0.5)$. The mean SASSY score was below the midpoint of the scale, indicating that participants endorsed the SDS to a limited extent. Also, no significant gender differences were found on gender investment $(t(109)=0.89, p=0.38)$. Female participants were found to score lower than male participants on the Extraversion subscale of the EPQ-R, and

Table 4 Hierarchical linear regressions of gender, explicit SDS endorsement, gender investment, extraversion, neuroticism, and social desirability on implicit SDS endorsement, and moderation by the interactions with gender

\begin{tabular}{|c|c|c|c|c|c|c|c|}
\hline & $B$ & $\mathrm{SE}$ & Beta & $t$ & $p$ & $95 \% \mathrm{CI}$ & \\
\hline \multicolumn{8}{|l|}{ Step $1 R^{2}=.08, F(2,107)=4.94, p=.009$} \\
\hline (Constant) & -.354 & 1.728 & .291 & -.205 & .838 & -3.779 & 3.071 \\
\hline Within-IAT Presentation Order & .219 & .071 & .002 & 3.096 & .003 & .079 & .359 \\
\hline Number of Valid IAT trials & .000 & .012 & & .017 & .987 & -.024 & .024 \\
\hline \multicolumn{8}{|c|}{ Step $2 R^{2}$ Change $=.13, F(6,101)=2.74, p=.017$} \\
\hline (Constant) & .165 & 1.690 & .245 & .098 & .922 & -3.188 & 3.518 \\
\hline Within-IAT Presentation Order & .185 & .072 & -.027 & 2.564 & .012 & .042 & .328 \\
\hline Number of Valid IAT trials & -.003 & .012 & .353 & -.293 & .770 & -.027 & .020 \\
\hline Gender & .286 & .078 & -.071 & 3.653 & .000 & .131 & .441 \\
\hline Explicit SDS Endorsement (SASSY) & -.027 & .035 & -.005 & -.770 & .443 & -.096 & .043 \\
\hline Gender Investment & -.002 & .035 & .142 & -.057 & .954 & -.070 & .067 \\
\hline Extraversion (EPQ-R) & .054 & .038 & -.004 & 1.432 & .155 & -.021 & .128 \\
\hline Neuroticism (EPQ-R) & -.001 & .036 & -.059 & -.039 & .969 & -.073 & .070 \\
\hline Social Desirability (EPQ-R) & -.022 & .036 & & -.612 & .542 & -.094 & .050 \\
\hline \multicolumn{8}{|c|}{ Step $3 R^{2}$ Change $=.06, F(5,96)=1.62, p=.162$} \\
\hline (Constant) & .176 & 1.700 & .234 & .103 & .918 & -3.200 & 3.551 \\
\hline Within-IAT Presentation Order & .176 & .072 & -.027 & 2.459 & .016 & .034 & .319 \\
\hline Number of Valid IAT trials & -.003 & .012 & .370 & -.293 & .770 & -.027 & .020 \\
\hline Gender & .299 & .083 & .384 & 3.609 & .000 & .135 & .463 \\
\hline Explicit SDS Endorsement (SASSY) & .145 & .108 & .030 & 1.340 & .183 & -.070 & .360 \\
\hline Gender Investment & .011 & .038 & .653 & .294 & .770 & -.064 & .086 \\
\hline Extraversion (EPQ-R) & .247 & .112 & .402 & 2.198 & .030 & .024 & .471 \\
\hline Neuroticism (EPQ-R) & .151 & .109 & .325 & 1.389 & .168 & -.065 & .366 \\
\hline Social Desirability (EPQ-R) & .122 & .113 & -.500 & 1.085 & .280 & -.101 & .346 \\
\hline Gender X Explicit SDS Endorsement & -.250 & .146 & -.074 & -1.712 & .090 & -.540 & .040 \\
\hline Gender X Gender Investment & -.056 & .075 & -.524 & -.744 & .458 & -.205 & .093 \\
\hline Gender X Extraversion & -.293 & .168 & -.433 & -1.742 & .085 & -.626 & .041 \\
\hline Gender X Neuroticism & -.236 & .158 & -.407 & -1.493 & .139 & -.550 & .078 \\
\hline Gender X Social Desirability & -.222 & .173 & & -1.285 & .202 & -.565 & .121 \\
\hline
\end{tabular}


higher on the Neuroticism and Social Desirability subscales (all $p<0.05$ ). Hierarchical regression analyses revealed that the gender difference on the SDS-IAT score remained significant after controlling for within-IAT presentation order, and number of valid IAT trials $(\beta=0.353, p<0.001)$, see Table 4 .

\section{Convergent and Divergent Validity of the SDS-IAT}

SDS-IAT scores did not correlate significantly with the related concept of explicit SDS endorsement, measured using the SASSY, nor with participants' scores on gender investment, see Table 5. In the female subsample, higher Extraversion was significantly associated with stronger implicit endorsement of a reverse SDS $(r=0.36$, $p<0.01, d=0.77)$. No other significant correlations with conceptually unrelated concepts were found.

Next, hierarchical multiple regression analysis using implicit SDS as dependent variable was performed on data of 111 participants. In the first step, presentation order, and number of valid IAT trials were entered as predictor variables. In the second step, gender, explicit SDS endorsement, Gender Investment, Extraversion, Neuroticism, and Social Desirability proneness were entered. In the third step, the interaction terms of gender and explicit SDS endorsement, Gender Investment, Extraversion, Neuroticism, and Social Desirability proneness were entered. Table 4 shows the results of the regression analysis. The full regression model was significant, $F(13,96)=2.79, p=0.002$; see Table 4 for regression statistics. In addition to Presentation Order $(\beta=0.23, p=0.016)$, Gender $(\beta=0.37, p<0.001)$, and Extraversion $(\beta=0.65, p=0.030)$ contributed significantly to the model. The interactions of predictor variables with gender were not significant.

\section{Discussion}

This study among heterosexual emerging adults investigated the psychometric characteristics of an Implicit Association Test aiming to measure implicit SDS endorsement. The reliability of the SDS-IAT was examined, and the attenuation-corrected alphas (practice trial 0.65 ; test trials 0.70 ; overall 0.67 ) were within the range of the reliability findings found for other IATs (Cunningham et al., 2001; Nosek et al.,

Table 5 Pearson correlations of implicit SDS endorsement measure using the IAT-SDS

\begin{tabular}{lll}
\hline & $\begin{array}{l}\text { Young } \\
\text { women } \\
(\mathrm{N}=75)\end{array}$ & $\begin{array}{l}\text { Young men } \\
(\mathrm{N}=38)\end{array}$ \\
\hline 1. Explicit SDS endorsement (SASSY) & -.05 & -.23 \\
2. Gender Investment & -.07 & .16 \\
3. Extraversion (EPQ) & $.36^{*}$ & -.05 \\
4. Neuroticism (EPQ) & .09 & -.20 \\
5. Social Desirability (EPQ) & -.06 & -.11 \\
\hline
\end{tabular}

$*=p<.01$ 
2007). This suggests that the measurement error of the SDS-IAT does not compromise the interpretation of the estimates of validity (Cronbach \& Meehl, 1955), even though it sets an upper limit for correlations (Werts et al., 1976). We found that young men and women both scored below the midpoint of the SASSY, reflecting a modest level of explicit endorsement of the SDS. No gender difference was found here. This finding matched the findings in previous studies using the same measure (Emmerink et al., 2016a, 2016b, 2017), as well as in other studies with other explicit SDS measures (Bordini \& Sperb, 2013; Crawford \& Popp, 2003). However, the present findings did not replicate the gender differences found by Sakaluk and Milhausen (2012), who found that, compared with women, men more strongly endorsed the explicit sexual double standard.

\section{Gender Differences}

Whereas the SDS-IAT showed a modest level of implicit SDS endorsement among men that was in line with their explicit SDS level, a reverse implicit SDS was revealed among young women. A reverse implicit double sexual standard implies that the "sexually active" construct is more closely connected with "female" (and "sexually passive" is more closely connected with "male") at an automatic level of processing. This pattern of findings is partially in line with those of Sakaluk and Milhausen (2012), who also found a reverse SDS in young women on an IAT measure of SDS endorsement, while young men's IAT responses showed a relatively gender-neutral implicit attitude towards the sexual standard. However, the effect size of the reverse implicit SDS in young women in the Sakaluk and Milhausen study (2012) was larger than in the current study $(M=|.31|$ vs. $M=|.08|)$. The dissimilar findings in both studies might be due to the use of different measures of explicit and implicit attitudes in both studies. Specifically, the SDS-IAT used in the present study used "sexually active vs sexually passive" as on-screen category labels, while the IAT in the study of Sakaluk and Milhausen used "sexually positive vs sexually negative". The observed dissimilarities might also be due to sampling differences, as the latter study was conducted among university students while the current study cast a wider net among relatives and acquaintances of university students, resulting in a more diverse sample with respect to education level.

But although the relative scores of young women and men in the two studies differed, the results are in the same direction, whilst both studies used different explicit scales and different IATs, which adds to the robustness and credibility of the findings. The repeatedly found gender differences regarding the explicit-implicit discrepancy can be speculated to be the result of multiple factors. If the implicit reverse SDS in young women is a manifestation of a social trend, resulting in the waning of the SDS favoring sexually active and dominant behavior in men, and the emergence of an SDS favoring this sexual behavior in women, these effects might be stronger in a study sample comprising only young adults in the more catalyzing university setting (Bryant, 2003). The trend towards gender-specific double sexual standards, with both young men and young women implicitly associating "being sexually active" with their own gender, and "being sexually passive with the opposite gender, can be 
interpreted as providing both genders with a self-serving bias function at an automatic level of processing (Mezulis et al., 2004; Paul et al., 1996), legitimating their own sexually active behavior. However, this implies that young women (also) see themselves as being sexually active and agentic (Klein et al., 2018; Mercer et al., 2013). Note that these findings do not yet reveal anything about the specific types of sexually active behaviors (e.g. socioemotional versus physical) young women and men have in mind, nor about the stage in the sexual interaction in which these behaviors are engaged in. However, the findings indicate once more that stereotypes of male and female sexual behaviors portray an all too simplified picture of a complex social reality. Future research might reveal whether the self-serving bias, or other interpersonal mechanisms, including the actor-observer bias (Jones \& Nisbett, 1987; Wilson et al., 1997) might offer relevant explanations for the present findings.

\section{Method-Related Effects}

Implicit SDS endorsement was found to be affected by presentation order of the two combinations of target and attribute categories within the SDS-IAT, which were counterbalanced in this study. Specifically, response latencies were smaller when the combination of "female" + "sexually passive" and "male + sexually active" was presented first, compared with the reverse presentation order. Similar order effects of within-IAT presentation of the two combinations of targets and attributes have also been found in previous research (Aberson \& Beeney, 2007; Mannarini \& Boffo, 2014; Mierke \& Klauer, 2003; Sakaluk \& Milhausen, 2012). Presentation order is said to be the most commonly observed method-specific factor affecting IAT effects (Greenwald \& Nosek, 2001). In general, the paired categories that are presented first during IATs yield stronger associations (Greenwald et al., 1998; Schnabel et al., 2008). Explanations for this finding consider the residual costs of task switching; tasks requiring cognitive effort enhance interference with subsequent tasks (Mierke \& Klauer, 2003; Nieuwenhuis \& Monsell, 2002). Method-related variance may have an impact on the psychometric properties of the SDS-IAT. It contaminates the estimates of inter-item consistency and retest reliability and decreases the convergent validity of the IAT (Mierke \& Klauer, 2003). Mierke and Klauer (2003) demonstrated that method-specific variance was reduced most effectively by computing IAT scores using the D measures for scaling IAT effects in units of standard deviations, while excluding very brief and very long reaction latencies (Greenwald, Nosek, and Banaji 2003), as we did in the present study. Implicit SDS endorsement was also found to be affected by number of valid IAT responses. Higher number of valid responses was associated with lower implicit SDS endorsement. This contaminating effect has also been found in studies using other IATs (Mannarini \& Boffo, 2014). However, in a study on faking behavior in IAT performance, intentional error commission was found to be an unsuccessful faking strategy (Röhner et al., 2013). It can therefore be recommended for future research using the SDS-IAT to check potential sources of method-specific variance and to control for such factors in the statistical approach. 


\section{Explicit-Implicit Discrepancy}

With regard to the convergent validity of the SDS-IAT, no significant correlations were found with a measure of explicit SDS endorsement, nor with general level of investment in gender ideals. Convergent validity with self-report measures measuring identical constructs, including explicit SDS endorsement, was not only expected to be low, based on previous meta-analytic data (Hofmann et al., 2005), but also on theoretical grounds. Theoretical accounts of implicit attitudes postulate the existence of separate information-processing modes (Greenwald \& Banaji, 1995) and, consequently, responses on measures that tap into these different processes, will inherently demonstrate low convergence (Cunningham et al., 2001).

Investigation of the divergent validity, by conducting correlation analysis of SDSIAT scores with scores on the conceptually unrelated concepts of extraversion, neuroticism, and social desirability proneness, showed that these constructs were largely independent: the correlations were not significant, except for Extraversion that correlated significantly, with a moderate effect size $(r=0.36)$, in female participants. However, when method-related factors (order of presentation and number of valid IAT responses) were controlled for in regression analysis, this moderating effect of gender was lost. The absence of a significant association of implicit SDS with social desirability is similar to the results of Sakaluk and Milhausen (2012). The SDS-IAT was thus found to show adequate divergent validity with non-neighboring constructs.

\section{Strenghts, Limitations, and Implications of the Present Study}

The present study aimed to further validate an implicit association test for measuring implicit endorsement of the sexual double standard. It was conducted among a sample of heterosexual emerging adults with a significant diversity of education and background. The results may help to investigate the impact of the sexual double standard in a changing world and across cultures.

The use of a convenience sample recruited among relatives and acquaintances of university students resulted in a skewed distribution of participants favoring women and more highly educated individuals. The demographic characteristics of the female and male subsamples differed: female participants were more often in a committed relationship than male participants. This gender difference cannot easily be explained. In the present sample, for instance, percentage of participants reporting that religion was important to them was not found to differ between female and male participants, nor between participants reporting being in a committed relationship vs. being single or dating.

Future psychometric studies of the SDS-IAT should address the stability of this measure by examining its test-retest reliability. Furthermore, the implicit aspects of the SDS should be compared across cultures, as well as in longitudinal research designs, to examine the relevance and pervasiveness of this aspect of gendered sexual attitudes under different cultural conditions. 


\section{Conclusion}

Taking note of these limitations, the measurement of implicit aspects of SDS endorsement may be fruitfully pursued using the SDS-IAT. We expect that future studies using the SDS-IAT can aid in disentangling the different levels of cognitive processing concerning SDS endorsement. A notable finding in the current study was that young women adhere to a reverse implicit SDS. This could indicate an important social trend that warrants further study.

Acknowledgements We thank students Edwin van den Berg, Kim Winters, Linda Wever, Niels Scheers, and Sanne Schepers for their contribution to the data collection.

Author Contributions All authors contributed to the study conception and design. Material preparation was performed by PE and JL; data collection was performed by PE; and analysis was performed by JL and RP-E. The first draft of the manuscript was written by JL and all authors commented on previous versions of the manuscript. All authors read and approved the final manuscript.

Funding No funding was received for this study.

Data Availability The data are available at: https://osf.io/3bsem/?view_only=1f0b4ec634494743a765 922d0c4f89df.

\section{Declarations}

Conflict of interest The authors have no conflicting interests to declare.

Ethical Approval The study was approved by the ethical review board of Utrecht University.

Consent for Publication Consent for publication was requested in the informed consent text.

Open Access This article is licensed under a Creative Commons Attribution 4.0 International License, which permits use, sharing, adaptation, distribution and reproduction in any medium or format, as long as you give appropriate credit to the original author(s) and the source, provide a link to the Creative Commons licence, and indicate if changes were made. The images or other third party material in this article are included in the article's Creative Commons licence, unless indicated otherwise in a credit line to the material. If material is not included in the article's Creative Commons licence and your intended use is not permitted by statutory regulation or exceeds the permitted use, you will need to obtain permission directly from the copyright holder. To view a copy of this licence, visit http://creativecommons.org/licen ses/by/4.0/.

\section{References}

Aberson, C. L., \& Beeney, J. (2007). Does substance use affect reliabilities of the implicit association test? Journal of Social Psychology, 147(1), 27-40. https://doi.org/10.3200/SOCP.147.1.27-40

Bermudez, M. P., Castro, A., Gude, F., \& Buela-Casal, G. (2010). Relationship power in the couple and sexual double standard as predictors of the risk of sexually transmitted infections and hiv: Multicultural and gender differences. Current HIV Research, 8(2), 172-178. https://doi.org/10. 2174/157016210790442669 
Bordini, G., \& Sperb, T. M. (2013). Sexual double standard: A review of the literature between 2001 and 2010. Sexuality \& Culture: An Interdisciplinary Quarterly, 17(4), 686-704. https://doi.org/ 10.1007/s 12119-012-9163-0

Brenner, G., Koller, M., \& Walla, P. (2019). Enhancing the implicit association test: A four-step model to find appropriate stimuli. In F. Davis, R. Riedl, J. vom Brocke, P. M. Léger, \& A. Randolph (Eds.), Information systems and neuroscience (pp. 111-118). Springer.

Bryant, A. N. (2003). Changes in attitudes toward women's roles: Predicting gender-role traditionalism among college students. Sex Roles, 48(3-4), 131-142. https://doi.org/10.1023/A:10224 51205292

Cohen, J., Cohen, P., West, S. G., \& Aiken, L. S. (2014). Applied multiple regression/correlation analysis for the behavioral sciences. Psychology Press.

Crawford, M., \& Popp, D. (2003). Sexual double standards: A review and methodological critique of two decades of research. Journal of Sex Research, 40(1), 13-26. https://doi.org/10.1080/00224 490309552163

Cronbach, L. J., \& Meehl, P. E. (1955). Construct validity in psychological tests. Psychological Bulletin, 52(4), 281-302. https://doi.org/10.1037/h0040957

Cunningham, W. A., Preacher, K. J., \& Banaji, M. R. (2001). Implicit attitude measures: Consistency, stability, and convergent validity. Psychological Science, 12(2), 163-170. https://doi.org/10.1111/ 1467-9280.00328

Cunningham, W. A., \& Zelazo, P. D. (2007). Attitudes and evaluations: A social cognitive neuroscience perspective. Trends in Cognitive Sciences, 11(3), 97-104. https://doi.org/10.1016/j.tics.2006.12.005

De Houwer, J. (2001). A structural and process analysis of the implicit association test. Journal of Experimental Social Psychology, 37(6), 443-451. https://doi.org/10.1006/jesp.2000.1464

Emmerink, P. M., van den Eijnden, R. J. J. M., ter Bogt, T. F. M., \& Vanwesenbeeck, I. (2017). A scale for the assessment of sexual standards among youth: Psychometric properties. Archives of Sexual Behavior, 46(6), 1699-1709. https://doi.org/10.1007/s10508-017-1001-x

Emmerink, P. M., van den Eijnden, R. J. J. M., Vanwesenbeeck, I., \& ter Bogt, T. F. M. (2016a). The relationship between endorsement of the sexual double standard and sexual cognitions and emotions. Sex Roles, 75(7-8), 363-376. https://doi.org/10.1007/s11199-016-0616-z

Emmerink, P. M., Vanwesenbeeck, I., van den Eijnden, R. J., \& Ter Bogt, T. F. (2016b). Psychosexual correlates of sexual double standard endorsement in adolescent sexuality. Journal of Sex Research, 53(3), 286-297. https://doi.org/10.1080/00224499.2015.1030720

Eysenck, H. J., \& Eysenck, S. B. G. (1975). Manual of the eysenck personality questionnaire. Hodder + Stoughton.

Fazio, R. H., \& Olson, M. A. (2003). Implicit measures in social cognition research: Their meaning and use. Annual Review of Psychology, 54, 297-327. https://doi.org/10.1146/annurev.psych.54.101601. 145225

Fugère, M. A., Escoto, C., Cousins, A. J., Riggs, M. L., \& Haerich, P. (2008). Sexual attitudes and double standards: A literature review focusing on participant gender and ethnic background. Sexuality \& Culture: An Interdisciplinary Quarterly, 12(3), 169-182. https://doi.org/10.1007/ s12119-008-9029-7

Goncalves, H., Behague, D. P., Gigante, D. P., Minten, G. C., Horta, B. L., Victora, C. G., \& Barros, F. C. (2008). Determinants of early sexual initiation in the Pelotas birth cohort from 1982 to 2004-5, Southern Brazil. Revista De Saude Publica, 42(Suppl 2), 34-41. https://doi.org/10.1590/S003489102008000900006

Good, J. J., \& Sanchez, D. T. (2010). Doing gender for different reasons: Why gender conformity positively and negatively predicts self-esteem. Psychology of Women Quarterly, 34(2), 203-214. https:// doi.org/10.1111/j.1471-6402.2010.01562.x

Greenwald, A. G., \& Banaji, M. R. (1995). Implicit social cognition: Attitudes, self-esteem, and stereotypes. Psychological Review, 102(1), 4-27. https://doi.org/10.1037/0033-295X.102.1.4

Greenwald, A. G., McGhee, D. E., \& Schwartz, J. L. (1998). Measuring individual differences in implicit cognition: The Implicit Association Test. Journal of Personality and Social Psychology, 74, 14641480. https://doi.org/10.1037/0022-3514.74.6.1464

Greenwald, A. G., \& Nosek, B. A. (2001). Health of the implicit association test at age 3. Zeitschrift Für Experimentelle Psychologie, 48(2), 85-93. https://doi.org/10.1026//0949-3946.48.2.85

Greenwald, A. G., Nosek, B. A., \& Banaji, M. R. (2003). Understanding and using the implicit association test: I-An improved scoring algorithm. Journal of Personality and Social Psychology, 85(2), 197-216. https://doi.org/10.1037/0022-3514.85.2.197 
Hofmann, W., Gawronski, B., Gschwendner, T., Le, H., \& Schmitt, M. (2005). A meta-analysis on the correlation between the implicit association test and explicit self-report measures. Personality and Social Psychology Bulletin, 31(10), 1369-1385. https://doi.org/10.1177/0146167205275613

Houben, K., \& Wiers, R. W. (2008). Measuring implicit alcohol associations via the internet: Validation of web-based implicit association tests. Behavior Research Methods, Instruments, \& Computers, 40(4), 1134-1143. https://doi.org/10.3758/BRM.40.4.1134

Jonason, P. K., \& Marks, M. J. (2009). Common vs uncommon sexual acts: Evidence for the sexual double standard. Sex Roles, 60(5-6), 357-365. https://doi.org/10.1007/s11199-008-9542-z

Jones, E. E., \& Nisbett, R. E. (1987). The actor and the observer: Divergent perceptions of the causes of behavior. In E. E. Jones, D. E. Kanouse, H. H. Kelley, R. E. Nisbett, S. Valins, \& B. Weiner (Eds.), Attribution: Perceiving the causes of behavior (pp. 79-94). Lawrence Erlbaum Associates.

Kiefer, A. K., \& Sanchez, D. T. (2007). Scripting sexual passivity: A gender role perspective. Personal Relationships, 14(2), 269-290. https://doi.org/10.1111/j.1475-6811.2007.00154.x

King, B. M., Duncan, L. M., Clinkenbeard, K. M., Rutland, M. B., \& Ryan, K. M. (2019). Social desirability and young men's self-reports of penis size. Journal of Sex \& Marital Therapy, 45(5), 452-455. https:// doi.org/10.1080/0092623X.2018.1533905

Klein, V., Becker, I., \& Štulhofer, A. (2018). Parenting, communication about sexuality, and the development of adolescent womens' sexual agency: A longitudinal assessment. Journal of Youth and Adolescence, 47(7), 1486-1498. https://doi.org/10.1007/s10964-018-0873-y

Mannarini, S., \& Boffo, M. (2014). An implicit measure of associations with mental illness versus physical illness: Response latency decomposition and stimuli differential functioning in relation to iat order of associative conditions and accuracy. PLOS ONE. https://doi.org/10.1371/journal.pone.0101911

Marks, M. J. (2008). Evaluations of sexually active men and women under divided attention: A social cognitive approach to the sexual double standard. Basic and Applied Social Psychology, 30(1), 84-91. https:// doi.org/10.1080/01973530701866664

Marks, M. J., \& Fraley, R. C. (2005). The sexual double standard: Fact or fiction? Sex Roles, 52(3-4), 175186. https://doi.org/10.1007/s11199-005-1293-5

Marks, M. J., \& Fraley, R. C. (2006). Confirmation bias and the sexual double standard. Sex Roles, 54(1-2), 19-26. https://doi.org/10.1007/s11199-006-8866-9

Marks, M. J., Young, T. M., \& Zaikman, Y. (2019). The sexual double standard in the real world: Evaluations of sexually active friends and acquaintances. Social Psychology, 50(2), 67-79. https://doi.org/10.1027/ 1864-9335/a000362

Mercer, C. H., Tanton, C., Prah, P., Erens, B., Sonnenberg, P., Clifton, S., Macdowall, W., Lewis, R., Field, N., Datta, J., Copas, A. J., Phelps, A., Wellings, K., \& Johnson, A. M. (2013). Changes in sexual attitudes and lifestyles in britain through the life course and over time: Findings from the national surveys of sexual attitudes and lifestyles (natsal). Lancet, 382(9907), 1781-1794. https://doi.org/10.1016/s01406736(13)62035-8

Mezulis, A. H., Abramson, L. Y., Hyde, J. S., \& Hankin, B. L. (2004). Is there a universal positivity bias in attributions? A meta-analytic review of individual, developmental, and cultural differences in the selfserving attributional bias. Psychological Bulletin, 130(5), 711-747. https://doi.org/10.1037/0033-2909. 130.5.711

Mierke, J., \& Klauer, K. C. (2003). Method-specific variance in the implicit association test. Journal of Personality and Social Psychology, 85(6), 1180-1192. https://doi.org/10.1037/0022-3514.85.6.1180

Milhausen, R. R., \& Herold, E. S. (1999). Does the sexual double standard still exist? Perceptions of university women. Journal of Sex Research, 36(4), 361-368. https://doi.org/10.1080/00224499909552008

Milhausen, R. R., \& Herold, E. S. (2001). Reconceptualizing the sexual double standard. Journal of Psychology \& Human Sexuality, 13(2), 63-83. https://doi.org/10.1300/J056v13n02_05

Moors, A., Spruyt, A., \& De Houwer, J. (2010). In search of a measure that qualifies as implicit: Recommendations based on a decompositional view of automaticity. In B. Gawronski \& B. K. Payne (Eds.), Handbook of implicit social cognition: Measurement, theory, and applications (pp. 19-37). The Guilford Press.

Muehlenhard, C., \& Quackenbush, D. (1996). The social meaning of women's condom use: The sexual double standard and women's beliefs about the meaning ascribed to condom use [Unpublished Manuscript].

Nieuwenhuis, S., \& Monsell, S. (2002). Residual costs in task switching: Testing the failure-to-engage hypothesis. Psychonomic Bulletin \& Review, 9(1), 86-92. https://doi.org/10.3758/BF03196259 
Nosek, B. A., Banaji, M. R., \& Greenwald, A. G. (2002). Harvesting implicit group attitudes and beliefs from a demonstration web site. Group Dynamics: Theory, Research, and Practice, 6(1), 101-115. https://doi. org/10.1037/1089-2699.6.1.101

Nosek, B. A., Greenwald, A. G., \& Banaji, M. R. (2007). The implicit association test at age 7: A methodological and conceptual review. In J. A. Bargh (Ed.), Social psychology and the unconscious: The automaticity of higher mental processes (pp. 265-292). Psychology Press.

Part, K., Rahu, K., Rahu, M., \& Karro, H. (2011). Gender differences in factors associated with sexual intercourse among estonian adolescents. Scandinavian Journal of Public Health, 39(4), 389-395. https:// doi.org/10.1177/1403494810395820

Paul, L., Foss, M. A., \& Baenninger, M. A. (1996). Double standards for sexual jealousy: Manipulative morality or a reflection of evolved sex differences? Human Nature, 7(3), 291-321. https://doi.org/10. 1007/BF02733399

R_Core_Team. (2021). R: A language and environment for statistical computing. Vienna, Austria. Retrieved 1 Sept 2021 from http://www.R-project.org.

Rasmussen, K. R., Grubbs, J. B., Pargament, K. I., \& Exline, J. J. (2018). Social desirability bias in pornography-related self-reports: The role of religion. Journal of Sex Research, 55(3), 381-394. https://doi.org/ 10.1080/00224499.2017.1399196

Röhner, J., Schröder-Abé, M., \& Schütz, A. (2013). What do fakers actually do to fake the iat? An investigation of faking strategies under different faking conditions. Journal of Research in Personality, 47(4), 330-338. https://doi.org/10.1016/j.jrp.2013.02.009

Sakaluk, J. K., \& Milhausen, R. R. (2012). Factors influencing university students' explicit and implicit sexual double standards. Journal of Sex Research, 49(5), 464-476. https://doi.org/10.1080/00224499.2011. 569976

Sanchez, D. T., \& Crocker, J. (2005). How investment in gender ideals affects well-being: The role of external contingencies of self-worth. Psychology of Women Quarterly, 29(1), 63-77. https://doi.org/10. 1111/j.1471-6402.2005.00169.x

Sanchez, D. T., Fetterolf, J. C., \& Rudman, L. A. (2012). Eroticizing inequality in the United States: The consequences and determinants of traditional gender role adherence in intimate relationships. Journal of Sex Research, 49(2-3), 168-183. https://doi.org/10.1080/00224499.2011.653699

Sanchez, D. T., \& Kiefer, A. K. (2007). Body concerns in and out of the bedroom: Implications for sexual pleasure and problems. Archives of Sexual Behavior, 36(6), 808-820. https://doi.org/10.1007/ s10508-007-9205-0

Sanderman, R., Eysenck, S. B., \& Arrindell, W. A. (1991). Cross-cultural comparisons of personality: The netherlands and england. Psychological Reports, 69, 1091-1096. https://doi.org/10.2466/PR0.69.8. 1091-1096

Schnabel, K., Asendorpf, J. B., \& Greenwald, A. G. (2008). Assessment of individual differences in implicit cognition: A review of iat measures. European Journal of Psychological Assessment, 24(4), 210-217. https://doi.org/10.1027/1015-5759.24.4.210

Shen, A.C.-T., Chiu, M.Y.-L., \& Gao, J. (2012). Predictors of dating violence among chinese adolescents: The role of gender-role beliefs and justification of violence. Journal of Interpersonal Violence, 27(6), 1066-1089. https://doi.org/10.1177/0886260511424497

Slabbinck, H., De Houwer, J., \& Van Kenhove, P. (2013). Convergent, discriminant, and incremental validity of the pictorial attitude implicit association test and the picture story exercise as measures of the implicit power motive. European Journal of Personality, 27(1), 30-38. https://doi.org/10.1002/per.1846

Truman, D. M., Tokar, D. M., \& Fischer, A. R. (1996). Dimensions of masculinity: Relations to date rape supportive attitudes and sexual aggression in dating situations. Journal of Counseling and Development, 74(6), 555-562. https://doi.org/10.1002/j.1556-6676.1996.tb02292.x

Vanwesenbeeck, I. (2009). Doing gender in sex and sex research. Archives of Sexual Behavior, 38(6), 883898. https://doi.org/10.1007/s10508-009-9565-8

Vanwesenbeeck, I. (2011). Diverse verlangens: Seksuele ontwikkeling onder moderne dubbele moraal [diverging desires: Sexual development according to the contemporary double standard]. Tijdschrift Voor Seksuologie [journal of Sexology], 35(4), 232-239.

Vecchione, M., Dentale, F., Alessandri, G., Imbesi, M. T., Barbaranelli, C., \& Schnabel, K. (2017). On the applicability of the big five implicit association test in organizational settings. Current Psychology, 36(3), 665-674. https://doi.org/10.1007/s12144-016-9455-x

Werts, C. E., Rock, D. A., Linn, R. L., \& Joreskog, K. G. (1976). Comparison of correlations, variances, covariances, and regression weights with or without measurement error. Psychological Bulletin, 83(6), 1007-1013. https://doi.org/10.1037/0033-2909.83.6.1007 
Wilson, S. R., Levine, K. J., Cruz, M. G., \& Rao, N. (1997). Attribution complexity and actor-observer bias. Journal of Social Behavior \& Personality, 12(3), 709-726.

Wood, W., Christensen, P. N., Hebl, M. R., \& Rothgerber, H. (1997). Conformity to sex-typed norms, affect, and the self-concept. Journal of Personality and Social Psychology, 73(3), 523-535.

Zaikman, Y., \& Marks, M. J. (2017). Promoting theory-based perspectives in sexual double standard research. Sex Roles, 76(7-8), 407-420. https://doi.org/10.1007/s11199-016-0677-z

Zapata-Calvente, A. L., Moya, M., Bohner, G., \& Megías, J. L. (2019). Automatic associations and conscious attitudes predict different aspects of men's intimate partner violence and sexual harassment proclivities. Sex Roles, 81(7-8), 439-455. https://doi.org/10.1007/s11199-019-1006-0

Publisher's Note Springer Nature remains neutral with regard to jurisdictional claims in published maps and institutional affiliations.

\section{Authors and Affiliations}

\section{Jacques J. D. M. van Lankveld ${ }^{1}$ (D) Peggy M. J. Emmerink ${ }^{2}$.} Regina J. J. M. van den Eijnden ${ }^{2} \cdot$ Tom F. M. ter Bogt ${ }^{2} \cdot$ Ron J. Pat-El $^{1}$. Ine Vanwesenbeeck ${ }^{2}$

1 Department of Psychology, Open University of the Netherlands, P.O. Box 2960, 6401 DL Heerlen, The Netherlands

2 Department of Interdisciplinary Social Sciences, Utrecht University, Padualaan 14, $3584 \mathrm{CH}$ Utrecht, The Netherlands 